Supplementary information of

\title{
Emission characteristics of refractory black carbon aerosols from fresh biomass burning: a perspective from laboratory experiment
}

Xiaole PAN et al.,

Correspondence to: panxiaole@mail.iap.ac.cn

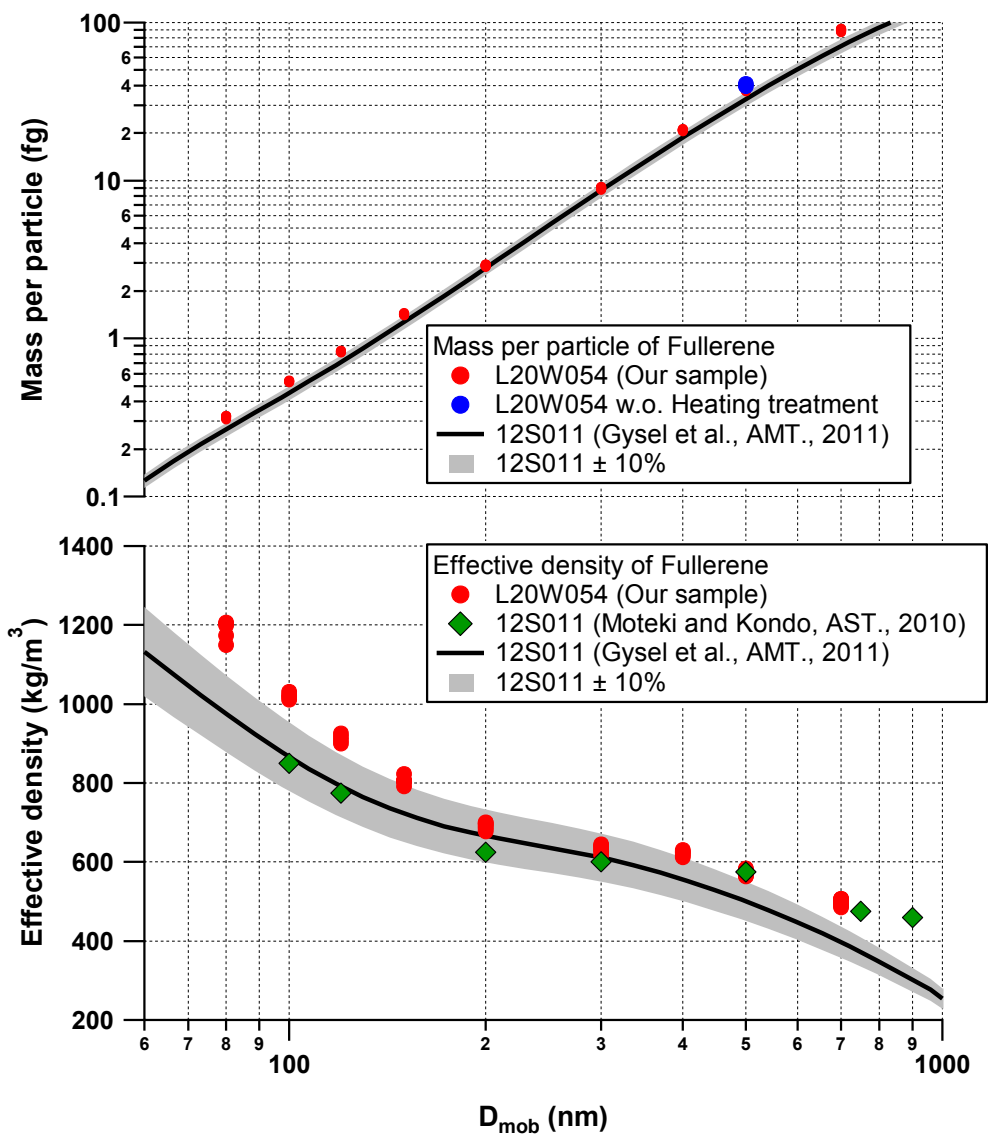

Figure. S1 The mass of FS particles and effective density as a function of is mobility diameter. The Effective density of FS particles was measured using a DMA-APM-CPC system. 


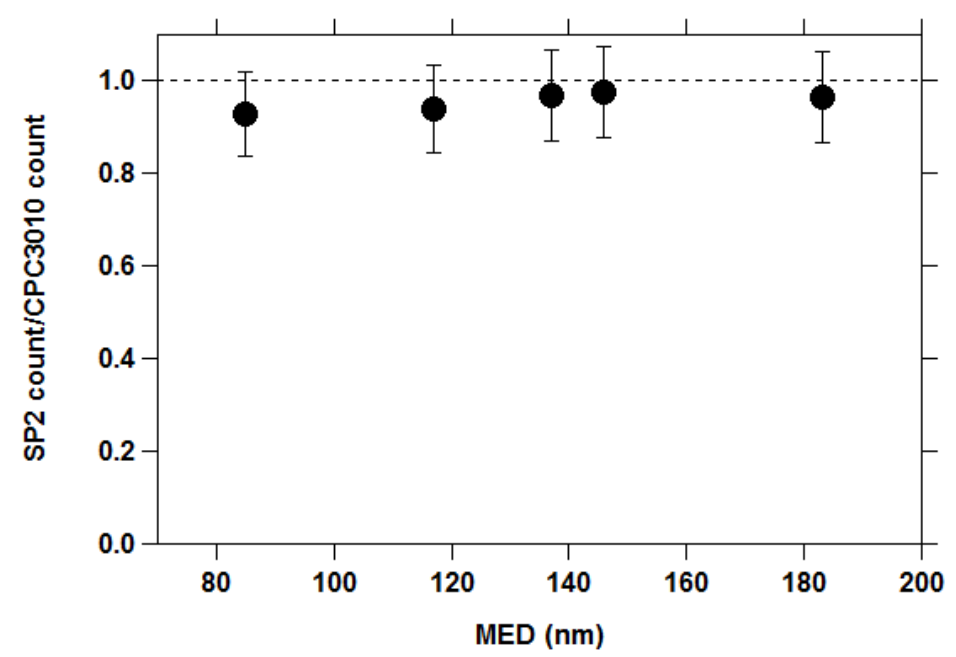

Figure S2. Detection efficiency of SP2 as a function of mass equivalent diameter of $\mathrm{rBC}$ particle at $80 \mathrm{~nm} \sim 190 \mathrm{~nm}$. The y-axis represents the count ratio between SP2 and CPC3010 measurements

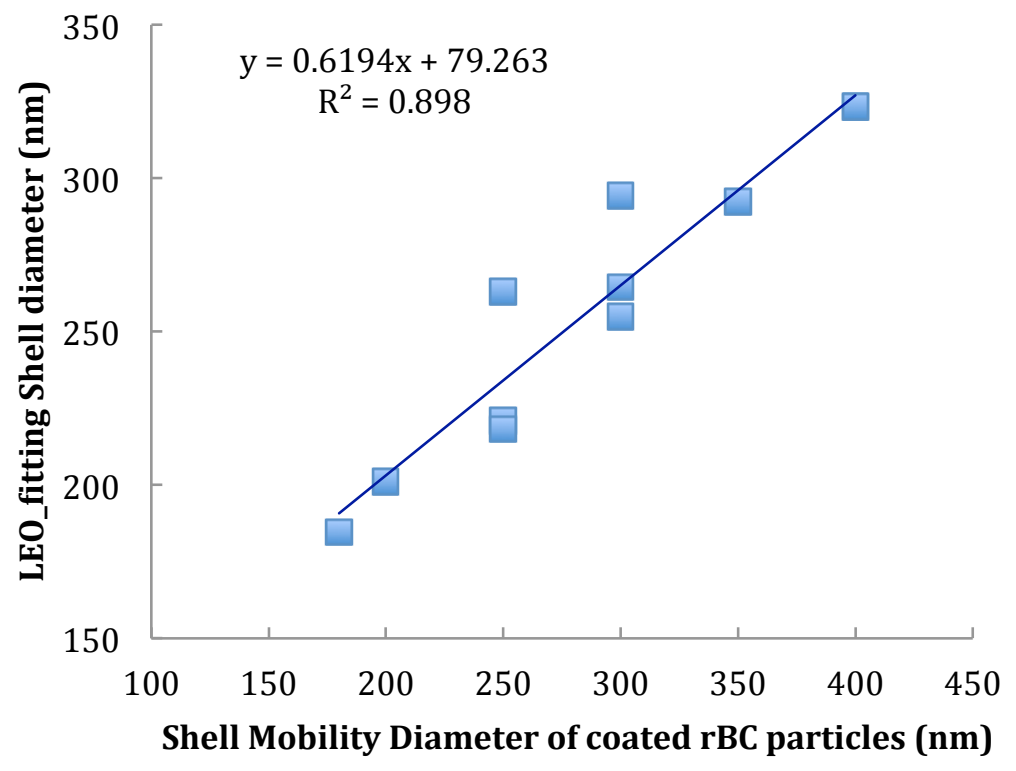

Figure S3. Scatter plot and linear regression of LEO_fitting Shell diameter of coated rBC and its Mobility diameter determined by Tandem DMA-SP2 system. 


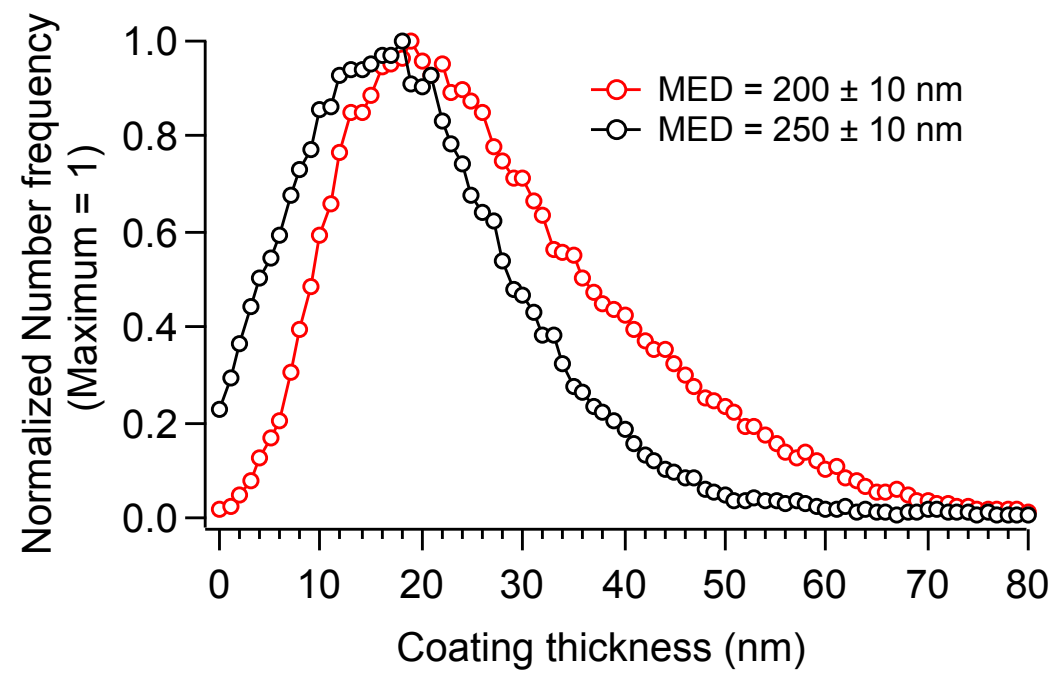

Figure S4. Coating thickness of $\mathrm{rBC}$ particles with $\mathrm{MED}=200 \pm 10 \mathrm{~nm}$ and $\mathrm{MED}=$ $250 \pm 10 \mathrm{~nm}$. 